\title{
The effects of chlorhexidine-based preservative tubes on routine urinalysis stability
}

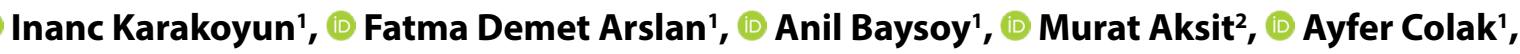 \\ Banu Isbılen Basok' \\ 'Department of Medical Biochemistry, University of Health Sciences, Tepecik Training and Research Hospital, Izmir, Turkey \\ ${ }^{2}$ Department of Medical Biochemistry, Giresun University, Prof. Dr. A. Ilhan Ozdemir Training and Research Hospital, Giresun, Turkey
}

\begin{abstract}
Objectives: To evaluate the effects of chlorhexidine-based preservative tubes on analytes for routine urinalysis. Methods: Urine specimen ( $\mathrm{n}=84)$ aliquots in polystyrene tubes (PS) with no additives (FIratmed Co. Ltd., Istanbul, Turkey) and in Becton-Dickinson Vacutainer ${ }^{\circledR}$ Plus Urinalysis Preservative (BD-UAP) tubes (Becton Dickinson Inc., NJ, USA) were analyzed on automatic modular urine analyzer (Dirui Industry, Changchun, China) and the results were compared. Stability was assessed by re-analyzing urine samples in BD-UAP tubes after three and six hours of storage and comparing with initial results. Cohen's kappa coefficient ( $\mathrm{k}$ ) was calculated to assess the agreement of results.

Results: Squamous epithelial cell and $\mathrm{pH}$ agreement between the tubes was moderate ( $\mathrm{k}=0.60$ and 0.58 , respectively). Bilirubin, ketone, protein, nitrite, and glucose showed perfect agreement with the PS tube and remained stable for up to six hours in the BD-UAP tube $(K=1.00,0.92,0.83,0.93,1.00$, respectively). Red blood cells, white blood cells, bacteria, blood, and leukocyte esterase showed moderate to substantial stability at six hours $(\kappa=0.56,0.77,0.76,0.87,0.57$, respectively).

Conclusion: Although storage in chlorhexidine-based preservative tubes has limited effects on chemical strip analysis, these tubes may not be considered optimal for microscopic examination.
\end{abstract}

Keywords: Chlorhexidine, preanalytical phase, storage, urinalysis, urine

$\mathrm{C}$ omplete urinalysis is one of the most commonly performed in vitro screening tests in clinical laboratories [1, 2]. In recent years, the utilization of fully automated urine analyzers has provided higher efficiency and accuracy in complete urinalysis tests [3]. As technological advances in the field have substantially improved the accuracy and precision of urinalysis, preanalytical requirements are now the more significant issue [4].

The Clinical and Laboratory Standards Institute (CLSI) guidelines [5] recommend completing urinalysis within two hours (hrs) of collection. However, if the analysis exceeds this period, storing samples in an uncontrolled temperature environment or without urine preservatives can compromise the quality of the results [2]. Although refrigeration reduces cell degradation and bacterial growth, it may impact the detection of other particles due to increased crystal formation [6].

Urine preservatives are commonly used to avoid bacterial overgrowth in culture samples [7]. Ethanol has traditionally been used as a preservative with or without polyethylene, and the use of boric acid and alternative preservatives has also been reported [8]. However, these preservatives may affect the chemical properties of the sample and change the appearance of existing particles [4]. These limitations have prompted manufacturers to evaluate various preservatives.

Address for correspondence: Inanc Karakoyun, MD. Department of Medical Biochemistry, University of Health Sciences, Tepecik Training and Research Hospital, Izmir, Turkey

Phone: +90 23246969 69/1734 E-mail: inanckara70@hotmail.com ORCID: 0000-0002-7057-171X

Submitted Date: May 22, 2020 Accepted Date: June 25, 2020 Available Online Date: October 05, 2020

${ }^{\circ}$ Copyright 2020 by International Journal of Medical Biochemistry - Available online at www.internationalbiochemistry.com OPEN ACCESS This work is licensed under a Creative Commons Attribution-NonCommercial 4.0 International License. 
Chlorhexidine is a cationic polybiguanide that has important antimicrobial properties [9]. The broad antimicrobial spectrum of chlorhexidine resulted in its widespread use as a disinfectant for the skin and in applications in the fields of ophthalmology, urology, gynecology, and otorhinolaryngology [9], and likely led to the idea of using chlorhexidine-based urine preservative tubes today.

The CLSI recommends that laboratories evaluate urine preservative systems before use [5]. In this context, the primary aim of this study was to assess the effects of Becton-Dickinson Vacutainer ${ }^{\circledast}$ Plus Urinalysis Preservative (BD-UAP) tube on analytes of urine aliquots stored at room temperature for up to six hrs. Proving the effectiveness of tubes containing preservatives in the storage of urine samples would make it possible to transfer samples from our satellite laboratories to our central laboratory.

\section{Materials and Methods}

This study was conducted between October 2019 and November 2019 in the University of Health Sciences Tepecik Training and Research Hospital. All patients provided written informed consent before participation and this study was conducted according to the criteria set by the declaration of Helsinki. Ethical approval was obtained from the hospital's local Ethics Committee (Date: September 9, 2019, no: 2019/14-17).

\section{Subjects}

Urine collection containers with identification barcodes were given by laboratory technicians to 84 randomly selected patients who were referred from different outpatient clinics to the urinalysis laboratory for complete urinalysis. Sample collection, transport, preparation, and urinalysis procedures were performed in line with European Urinalysis Guidelines [10]. Patients were asked to collect a clean catch urine sample of sufficient volume (at least $80 \mathrm{~mL}$ ) in the morning and bring the sample to the laboratory within 10 minutes. Excessively mucoid, viscous samples and samples with macrohematuria were excluded from this study.

\section{Methods}

Urine samples were transferred to two different tubes:

1. Polystyrene (PS) tube with no additives (Ref no. 8870000008; Firatmed Co. Ltd., Istanbul, Turkey), $10 \mathrm{~mL}$.

2. Becton-Dickinson Vacutainer ${ }^{\circledast}$ Plus Urinalysis Preservative (BD-UAP) tube (Ref no. 364992; Becton Dickinson Inc., New Jersey, USA), $8 \mathrm{~mL}$.

The BD-UAP tubes assessed in this study were polyethylene terephthalate plastic tubes spray-coated with $0.4 \%$ chlorhexidine, $5.6 \%$ ethylparaben, and $94 \%$ sodium propionate. Urine samples in the BD-UAP tubes were inverted 8-10 times as per the manufacturer's instructions and stored at room temperature $\left(20-25^{\circ} \mathrm{C}\right)$ protected from light. Analyses were performed within one hr of collection for both the PS tubes and BD-UAP tubes $(0 \mathrm{hr})$ and repeated three and six hrs later for the BDUAP tubes only.

$\mathrm{H}-800$ and FUS-200 fully automated urine analyzers (Dirui Industrial Co., Changchun, China) were used for the analyses. $\mathrm{H}-800$ urine chemistry analyzer module is a reflectance photometer that measures the density of colorimetric changes in the strips and transforms those into categorical or semiquantitative data. Original $\mathrm{H}-800$ strips (Dirui Industrial Co., Changchun, China) were used in this study and the chemical tests (specific gravity, $\mathrm{pH}$, urobilinogen, bilirubin, ketone, blood, protein, nitrite, leukocyte esterase, and glucose) were reported semiquantitatively. The within-run percent coefficient of variation (CV\%) values for specific gravity, $\mathrm{pH}$, urobilinogen, bilirubin, ketone, blood, protein, nitrite, leukocyte esterase, and glucose were $4.6,2.5,3.4,3.5,4.0,2.3,6.4,2.5,3.3$, and 5.2 , respectively.

The FUS-200 urine sediment analyzer adopts flow cell digital imaging technology with an artificial intelligence identification technique. The urine is illuminated as it passes through the flow cell and images are recorded with a digital camera placed on the lens of the microscope. These images are transferred to the computer, where software classifies and transmits them to the screen to be evaluated by the operator. Assessment of sediment images in our study was performed by a single laboratory specialist. Original calibrator and control material supplied by the manufacturer were used for daily calibration and quality control procedures, also according to the manufacturer's instructions. The within-run CV\% of the FUS-200 analyzer was 8.8 .

\section{Statistical analysis}

Statistical analyses were performed using SPSS v.20 software (IBM, NY, USA). All parameters except specific gravity and $\mathrm{pH}$ were dichotomized as positive or negative. Thresholds for positive red blood cell (RBC), white blood cell (WBC), squamous epithelial cell, and bacteria results were $17 \times 10^{6} / \mathrm{L}, 28 \times 10^{6} / \mathrm{L}$, $22 \times 10^{6} / \mathrm{L}$ and $6 \times 10^{6} / \mathrm{L}$, respectively [6]. For chemical parameters, results of trace and above were classified as positive. Because PS tubes are used in standard routine laboratory procedures, $0-\mathrm{hr}$ results of these tubes were used as a reference, and the agreement of the BD-UAP tube results was tested. Additionally, BD-UAP results from $0 \mathrm{hr}$ were compared to 3and 6-hr results. Cohen's kappa coefficient (K) was calculated to assess the agreement of results [11]. $\mathrm{K}$ values in the ranges of $0.41-0.60,0.61-0.80$ and $0.81-1.00$ were defined as moderate, substantial, and perfect agreement, respectively [12]. A cut-off value of $\mathrm{k}=0.80$ was determined, and analytes with $\mathrm{K}$ values $>0.80$ were regarded as having an acceptable agreement. $\mathrm{pH}$ values were evaluated as ordinal data $(<7.00 \mathrm{acid}$, $=7.00$ neutral, and $>7.00$ alkaline) while specific gravity was considered continuous data; $\mathrm{k}$ value was used to assess the agreement between $\mathrm{pH}$ values. For specific gravity, normality of the data distribution was evaluated with Shapiro-Wilk test 
and statistical differences were evaluated using paired t-test. P-value $<0.05$ was considered significant.

\section{Results}

The manufacturer's cut-off values and numbers of pathologic urine samples for each parameter are presented in Table 1. Of the 84 samples examined, 80 samples were acidic and four samples had a neutral $\mathrm{pH}$. Urobilinogen was excluded from statistical analyses because too few samples that were tested were positive.

Mean ( \pm standard deviation) specific gravity at $0 \mathrm{hr}$ was $1017 \pm 5.97$ in the PS tubes and $1018 \pm 6.04$ in the BD-UAP tubes $(p<0.001)$. At three and six hrs, specific gravity in the BD-UAP tubes was $1018 \pm 6.32$ and $1018 \pm 6.25$, respectively. There was no significant change in specific gravity at either time point compared to the initial value ( 0 vs. 3 hrs: $p=0.290 ; 0$ vs. 6 hrs: $\mathrm{p}=0.310$ ).

When assessed for its efficiency in preserving urine parameters, BD-UAP tubes showed the best agreement with the reference tube for the parameters nitrite and glucose (Table 2). Perfect agreement was observed for bilirubin, ketone, blood, protein, and leukocyte esterase parameters. RBC, WBC, and bacteria parameters showed substantial agreement. Moderate agreement was observed for squamous epithelial cells and $\mathrm{pH}$.

Showing perfect agreement with the reference tube, bilirubin, ketone, protein, nitrite, and glucose were stable in BD-UAP tubes up to six hrs (Table 3 ). Glucose showed perfect agreement with the reference tube and was also the most stable parameter at six hrs. Blood demonstrated perfect agreement with the reference tube at $0 \mathrm{hr}$, substantial agreement at three

Table 1. Manufacturer's cut-off values and pathological urine samples

\begin{tabular}{lll}
\hline Analyte & Manufacturer's cut-off values & Pathologic urine samples, $\mathbf{n}$ (\%) \\
\hline Specific gravity $(\mathrm{kg} / \mathrm{L})$ & $1005-1025$ & $6(7.1)$ \\
$\mathrm{pH}$ & $5.5-8.0$ & $0(0)$ \\
Urobilinogen $(\mu \mathrm{mol} / \mathrm{L})$ & Negative & $0(0)$ \\
Bilirubin $(\mu \mathrm{mol} / \mathrm{L})$ & Negative & $5(6.0)$ \\
Ketone $(\mathrm{mmol} / \mathrm{L})$ & Negative & $15(17.8)$ \\
Blood (erythrocytes/ $\mu \mathrm{L})$ & 10 & $58(69.0)$ \\
Protein $(\mathrm{g} / \mathrm{L})$ & 0.3 & $26(31.0)$ \\
Nitrite $(\mu \mathrm{mol} / \mathrm{L})$ & Negative & $7(8.3)$ \\
Leukocyte esterase $(\mathrm{leukocytes} / \mu \mathrm{L})$ & $36(42.9)$ \\
Glucose $(\mathrm{mmol} / \mathrm{L})$ & 15 & $8(9.5)$ \\
Red blood cells $\left(\mathrm{x} 10^{6} / \mathrm{L}\right)$ & 5.6 & $37(44.0)$ \\
White blood cells $\left(\mathrm{x} 10^{6} / \mathrm{L}\right)$ & 17 & $28(33.3)$ \\
Squamous epithelial cells $\left(\mathrm{x} 10^{6} / \mathrm{L}\right)$ & 28 & $28(33.3)$ \\
Bacteria $\left(\mathrm{x} 10^{6} / \mathrm{L}\right)$ & 28 & $27(32.1)$ \\
\hline
\end{tabular}

Table 2. Agreement of initial values (0-hour) in polystyrene tubes with no additive and Becton-Dickinson Vacutainer ${ }^{\circledR}$ Plus Urinalysis Preservative tubes

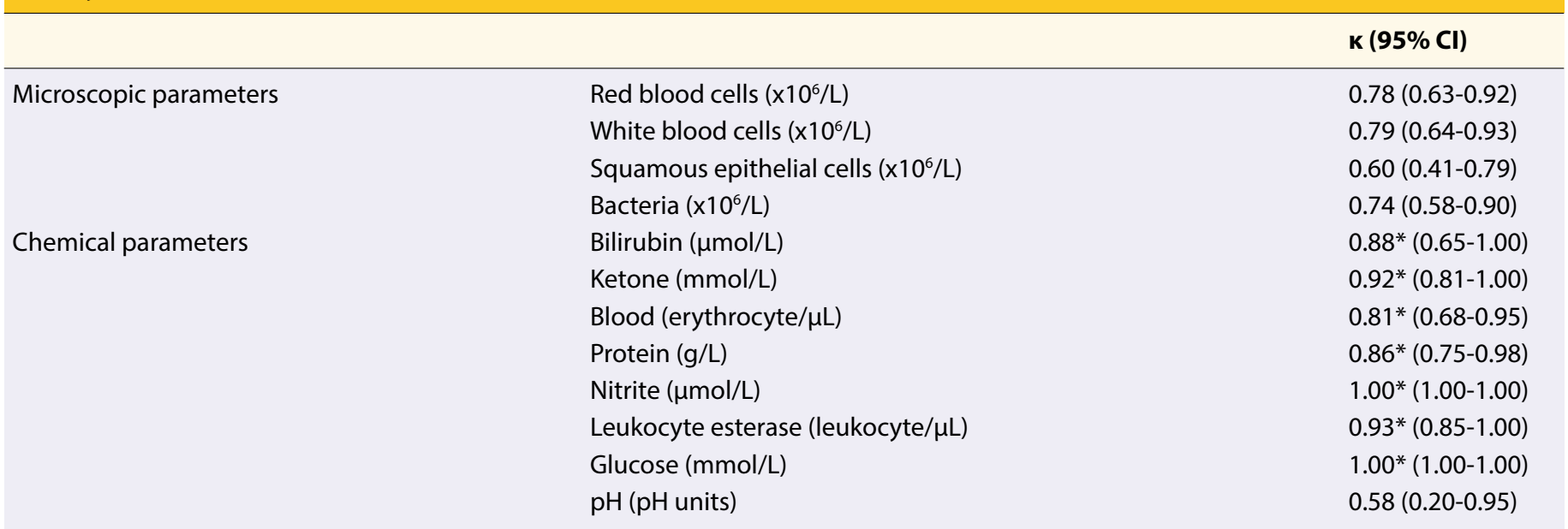

K: Kappa coefficient, $\mathrm{Cl}$ : Confidence interval. *Analytes that had an acceptable agreement in the BD UAP tubes compared to the reference tubes ( $\mathrm{K}>0.80$ ) 
Table 3. Agreement of analytes stored in Becton-Dickinson Vacutainer ${ }^{\circledR}$ Plus Urinalysis Preservative (BD-UAP) tubes after three and six hours of storage compared to initial results

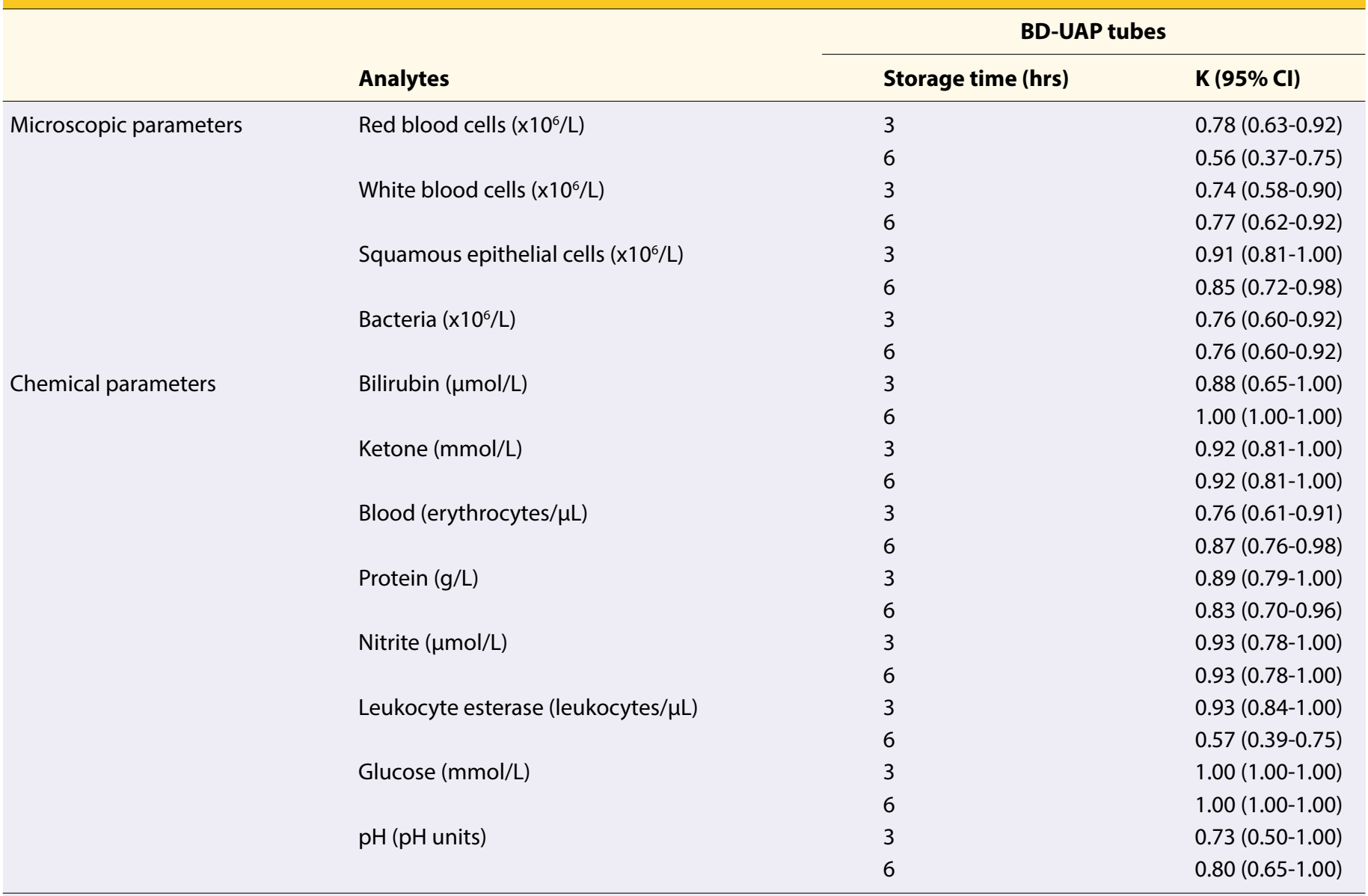

к: Kappa coefficient, Cl: Confidence interval

hrs, and perfect agreement again at six hrs. Leukocyte esterase remained stable until three hrs but showed only moderate agreement at six hrs.

WBC and bacteria parameters showed substantial agreement with the reference tube and their agreement did not change up to six hrs, whereas RBC stability deteriorated and the level of agreement fell from substantial to moderate at six hrs.

Squamous epithelial cells and $\mathrm{pH}$ had a moderate agreement with the reference tube and showed better stability.

\section{Discussion}

This study comparing a chlorhexidine-based preservative tube with a reference tube with no additives revealed varying degrees of agreement and stability in the chlorhexidine tube. The most important finding from this study is that bilirubin, ketone, protein, nitrite, and glucose analytes can be stored for up to six hrs in this chlorhexidine-based preservative tube. The second noteworthy finding of this study that chemical parameters generally yield better agreement and stability results than microscopic parameters.
Compared with the reference tube, the parameters with a perfect agreement in BD-UAP tubes were bilirubin, ketone, blood, protein, nitrite, leukocyte esterase, and glucose. All of these parameters, except blood remained stable up to three hrs. $\mathrm{RBC}, \mathrm{WBC}$, bacteria, squamous epithelial cells, and $\mathrm{pH}$ showed moderate to a substantial agreement with the reference tube. At six hrs, both leukocyte esterase and RBC showed a substantial loss of stability.

In our study, chemical parameters generally yielded better agreement and stability results than microscopic parameters. Considering the European urine analysis guideline [10] states that particle analysis can be conducted up to four hrs after collection while analysis of test strip parameters can be done up to $24 \mathrm{hrs}$ for samples stored at $4^{\circ} \mathrm{C}$, our findings are not surprising. The lower stability of particle parameters may be related to chemical preservatives causing degradation and morphological changes in the cell membranes of RBC and WBC due to osmotic effects [13]. In previous studies, false high RBC counts were reported due to the misclassification of yeast [14]. However, this parameter was not included in our study due to problems frequently encountered in the measurement of yeast in automatic 
urine sediment analysis [15]. Prolonged storage of urine may cause an increase in $\mathrm{pH}$ due to urease-producing Proteus spp., and particle lysis may accompany high $\mathrm{pH}$ values. However, the low agreement in $\mathrm{pH}$ starting at $\mathrm{O}$ hrs indicates that the $\mathrm{pH}$ shift was caused by the urine preservative, not bacterial growth.

The literature includes conflicting reports regarding tubes from different manufacturers with different preservatives. In contrast to our findings, Ercan et al. evaluated 48 samples and found that most chemical and microscopic parameters remained stable until $72 \mathrm{hrs}$ when transferred in tubes stored at room temperature with chlorhexidine as a preservative. They noted that RBC lost stability at $72 \mathrm{hrs}$, while WBC showed instability at $24 \mathrm{hrs}$ [6].

Kouri et al. examined 224 samples in tubes with no additives and demonstrated that chemical parameters were unaffected when transferred within eight hrs at $+20^{\circ} \mathrm{C}$. They reported that tubes containing chlorhexidine, boric acid, and Stabilur ${ }^{\circledR}$ as preservatives yielded acceptable results for the same duration in strip analysis and particle counting or bacteria culture if required, and that preservative tubes might be able to extend this 8-hr stability period for both chemical and microscopic parameters [16].

In their study conducted with 84 samples, Avcl et al. found that tubes containing chlorhexidine as a preservative and transported more than two hrs yielded unaffected results for all parameters within the same day [17].

Ekşioğlu et al. reported comparable results to our study. They examined 275 samples for stability up to 48 hrs in tubes containing chlorhexidine and found that the preservative tubes did not meet the preanalytical criteria for chemical analysis or particle counting. The authors concluded based on their results that transporting urinary samples for the centralization of urinalysis was not yet feasible without impacting the results [13].

Literature evaluating the effects of preservative tubes on chemical and microscopic parameters is scarce. In addition, most studies that utilized these tubes were focused on analyses that aimed to preserve bacterial content. The discrepancies between studies using the tubes with the same preservatives produced by the same manufacturers may be due to variations in the number of total samples, number of pathological samples and statistical methods applied. While Ercan and Avcı analyzed their results as a simple percentage of agreement, Kouri adopted error ratios and Ekşioğlu used FN and FP rates along with $\mathrm{k}$ values for concordance analysis. One of the factors causing conflict between studies is the different cutoff values used by authors for $\mathrm{K}$ value. Although the $\mathrm{k}$ range $0.41-0.60$ is classified as moderate, $0.61-0.80$ as substantial and $0.81-1.00$ as perfect agreement, studies in the health field emphasize that 0.80 should be used as the lower threshold for acceptable agreement [18]. In the present study, we also accepted 0.80 as the cut-off and aimed for parameters to have near-perfect agreement results in our evaluation of preservative tubes for sample storage. If we had adopted a cut-off value of 0.60 for acceptability, we would have determined that all BD-UAP parameters except $\mathrm{pH}$ and specific gravity were in agreement with the reference tube at $0 \mathrm{hr}$ and that all parameters remained stable until three hrs. As we reached six hrs, only RBC and leukocyte esterase would have lost stability. Therefore, in this scenario, tubes containing chlorhexidine would have provided adequate transport conditions for all parameters but $\mathrm{pH}$ and specific gravity within three hrs.

This study demonstrates that in addition to consulting the literature regarding urinalysis preservative tubes, laboratory physicians must also conduct their own evaluation before using these tubes, consistent with CLSI recommendations.

The findings in this study are subject to some limitations. First, manual microscopic examination, the gold standard for particle counting [19], was not performed in our study, and secondly, we did not have any samples with alkaline $\mathrm{pH}$ levels. Thirdly, stability analysis was limited to only six hrs. However, this study aimed to evaluate the efficiency of transferring urine samples from our peripheral satellite laboratories to our central laboratory, which takes no longer than six hrs. Another limitation was that analyses were not repeated at three and six hrs for the reference tubes with no additive.

\section{Conclusion}

In conclusion, although storage in a chlorhexidine-based preservative tube has a limited effect on chemical strip analysis, it may not be considered an optimal tube for microscopic examination.

Conflict of Interest: No potential conflict of interest was reported by the authors.

Ethics Committee Approval: Ethical approval was obtained from the hospital's local Ethics Committee (Date: September 9, 2019, no: 2019/14-17).

Financial Disclosure: This research received no specific grant from any funding agency in the public, commercial, or not-forprofit sectors.

Peer-review: Externally peer-reviewed.

Authorship Contributions: Concept - I.K., F.D.A., A.B., M.A., A.C., B.I.B.; Design - I.K., F.D.A., A.B., M.A., A.C., B.I.B.; Supervision - I.K., F.D.A., A.B., M.A., A.C., B.I.B.; Funding - None; Materials - .A.B., M.A.; Data collection \&/or processing - I.K., A.B., M.A.; Analysis and/or interpretation - I.K., F.D.A., B.I.B.; Literature search - I.K., A.B., M.A.; Writing - I.K.; Critical review - I.K., F.D.A., A.C., B.I.B.

\section{References}

1. Coppens A, Speeckaert M, Delanghe J. The pre-analytical challenges of routine urinalysis. Acta Clin Belg 2010;65(3):182-9.

2. Delanghe J, Speeckaert M. Preanalytical requirements of urinalysis. Biochem Med (Zagreb) 2014;24(1):89-104. [CrossRef]

3. Foudraine DE, Bauer MP, Russcher A, Kusters E, Cobbaert CM, van der Beek MT, et al. Use of Automated Urine Microscopy 
Analysis in Clinical Diagnosis of Urinary Tract Infection: Defining an Optimal Diagnostic Score in an Academic Medical Center Population. J Clin Microbiol 2018;56(6):e02030-17.

4. Delanghe JR, Speeckaert MM. Preanalytics in urinalysis. Clin Biochem 2016;49(18):1346-50. [CrossRef]

5. Clinical and Laboratory Standards Institute. Urinalysis; approved guideline-third edition. CLSI document: GP16-A3. Wayne, PA, USA: CLSI; 2009.

6. Ercan $M$, Akbulut ED, Abuşoğlu S, Yılmaz FM, Oğuz EF, Topçuoğlu C, et al. Stability of urine specimens stored with and without preservatives at room temperature and on ice prior to urinalysis. Clin Biochem 2015;48(13-14):919-22. [CrossRef]

7. Daley P, Gill Y, Midodzi W. Comparison of clinical performance of commercial urine growth stabilization products. Diagn Microbiol Infect Dis 2018;92(3):179-82. [CrossRef]

8. Kouri T, Vuotari L, Pohjavaara S, Laippala P. Preservation of urine for flow cytometric and visual microscopic testing. Clin Chem 2002;48(6 Pt 1):900-5. [CrossRef]

9. Gomes BP, Vianna ME, Zaia AA, Almeida JF, Souza-Filho FJ, Ferraz CC. Chlorhexidine in endodontics. Braz Dent J 2013;24(2):89-102. [CrossRef]

10. European Confederation of Laboratory Medicine. European urinalysis guidelines. Scand J Clin Lab Invest Suppl 2000;231:1-86.

11. Cohen J. A coefficient of agreement for nominal scales. Educ Psychol Meas 1960;20:37-46. [CrossRef]
12. D.G. Altman, Practical Statistics for Medical Research. London: Chapman and Hall; 1991.

13. Ekşioğlu MK, Madenci ÖÇ, Yücel N, Elçi A, Turhan B, Orhan $G$, et al. The effectiveness of BD Vacutainer ${ }^{\circledast}$ Plus Urinalysis Preservative Tubes in preservation of urine for chemical strip analysis and particle counting. Biochem Med (Zagreb) 2016;26(2):224-32. [CrossRef]

14. Manoni F, Tinello A, Fornasiero L, Hoffer P, Temporin V, Valverde $S$, et al. Urine particle evaluation: a comparison between the UF-1000i and quantitative microscopy. Clin Chem Lab Med 2010;48(8):1107-11. [CrossRef]

15. Aydin O, Ellidag HY, Eren E, Yilmaz N. High False Positives and False Negatives in Yeast Parameter in an Automated Urine Sediment Analyzer. J Med Biochem 2015;34(3):332-7. [CrossRef]

16. Kouri T, Malminiemi O, Penders J, Pelkonen V, Vuotari L, Delanghe J. Limits of preservation of samples for urine strip tests and particle counting. Clin Chem Lab Med 2008;46(5):70313. [CrossRef]

17. Avci E, Aybek H, Kangal Z, Ceken N, Kucuk IG, Gezer Y. The role of tubes with preservative in urinalysis of pregnant women. Medicine Science 2018;7(3):610-2. [CrossRef]

18. McHugh ML. Interrater reliability: the kappa statistic. Biochem Med (Zagreb) 2012;22(3):276-82. [CrossRef]

19. Langlois MR, Delanghe JR, Steyaert SR, Everaert KC, De Buyzere ML. Automated flow cytometry compared with an automated dipstick reader for urinalysis. Clin Chem 1999;45(1):118-22. 